\title{
Analysis and Comparison of Surface Roughness Effects on Pressure Data from SLS Wind Tunnel Test
}

Presented By: Autumn N. Douthitt

Mentor: Nettie H. Roozeboom

NASA Ames Summer 2019 Internship Branch Presentation 


\section{Mission Objective}

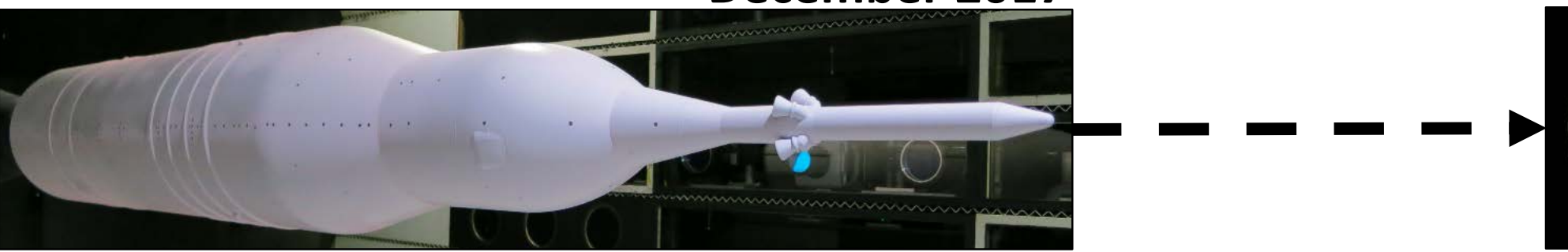

- Necessary to know flow field characteristics of SLS design configurations

- Does paint application affect signal?

- Does sanding of the paint affect signal? around the Kulite
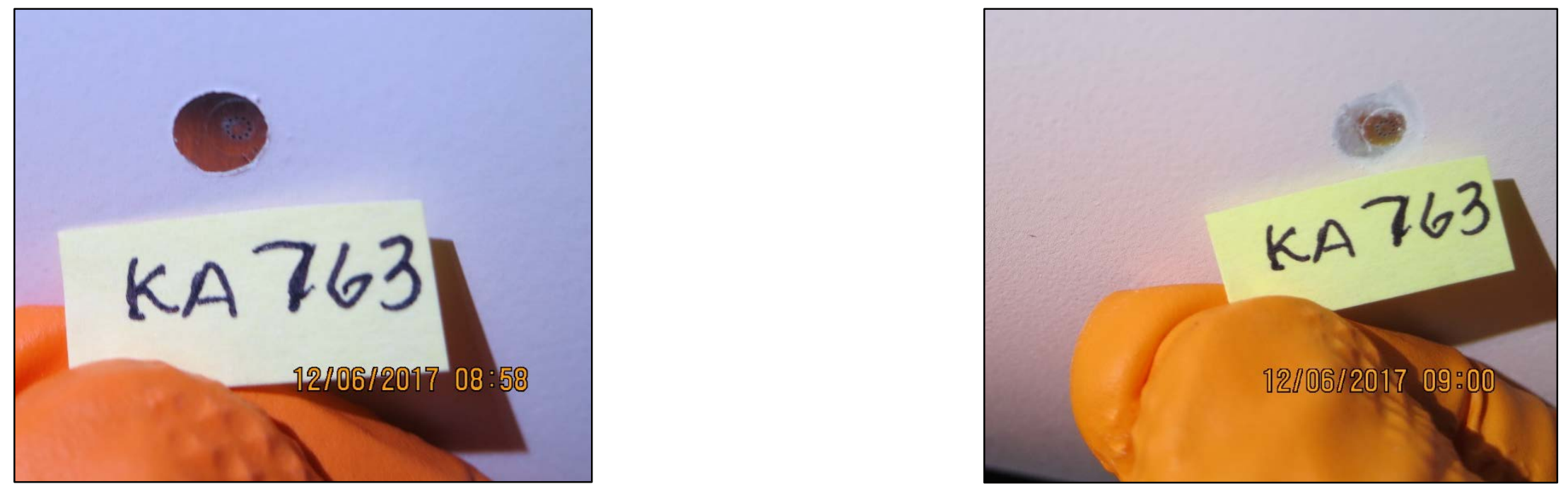

Sanded paint around the Kulite 


\section{Kulite Locations on SLS}

\begin{tabular}{|c|c|c|c|c|}
\hline$\#$ & Kulite & Zone & $\mathbf{X}$ & Phi \\
\hline 1 & 738 & 13 & 43.1 & 283 \\
\hline 2 & 996 & 77 & 53.4 & 270 \\
\hline 3 & 404 & 77 & 53.4 & 180 \\
\hline 4 & 763 & 77 & 55.9 & 90 \\
\hline 5 & 773 & 77 & 58.5 & 113 \\
\hline 6 & 779 & 77 & 58.5 & 293 \\
\hline 7 & 792 & 78 & 60.7 & 225 \\
\hline 8 & 414 & 78 & 61.4 & 45 \\
\hline 9 & 416 & 78 & 61.4 & 182 \\
\hline 10 & 419 & 79 & 62.2 & 93 \\
\hline 11 & 998 & 79 & 65.4 & 270 \\
\hline 12 & 925 & 79 & 66.6 & 315 \\
\hline 13 & 923 & 79 & 66.6 & 239 \\
\hline 14 & 940 & 90 & 69.8 & 270 \\
\hline 15 & 952 & 99 & 72.4 & 225 \\
\hline
\end{tabular}

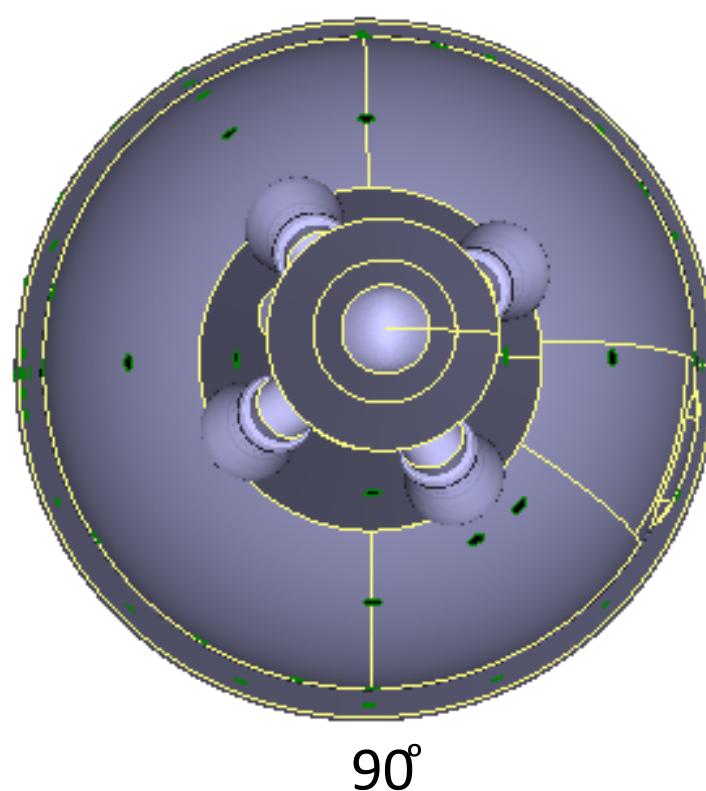

Day 0

Day 1

Day 2

Day 3

\begin{tabular}{l||r|l|l|l} 
Mach & Run Number & Run Number & Run Number & Run Number \\
\hline
\end{tabular} 0.7

0.8

129

1322

1280

1323

0.85

0.9

0.95

1.05

1.1

1.2

1265

1324

1250

1325

1235

1326

1220

1327

1205

1328

1190

1329

1.4

1175

1330

1354
1355
1356
1357
1358
1359
1360
1361
1362

1406

1407

1408

1409

1410

1411

1412

1413

1414 


\title{
Tools for Mission Success
}

1. Notes, Pictures, and Run Log from Test

2. Reduced Kulite and uPSP Pressure Time History Data 3. Matlab $\rightarrow$ Plot 3D and Modified uPSP Example Code
4. Dots
5. Requirements of SLS Customers

西




\section{Processing the Kulite Data}




\section{Locating Kulites on SLS using Dots}

- Began with studying documentation taken during Kulite sanding (photos, notes, test run $\log )$

- Using Dots, was able to

Kulite names can be featured beside their location

Flow

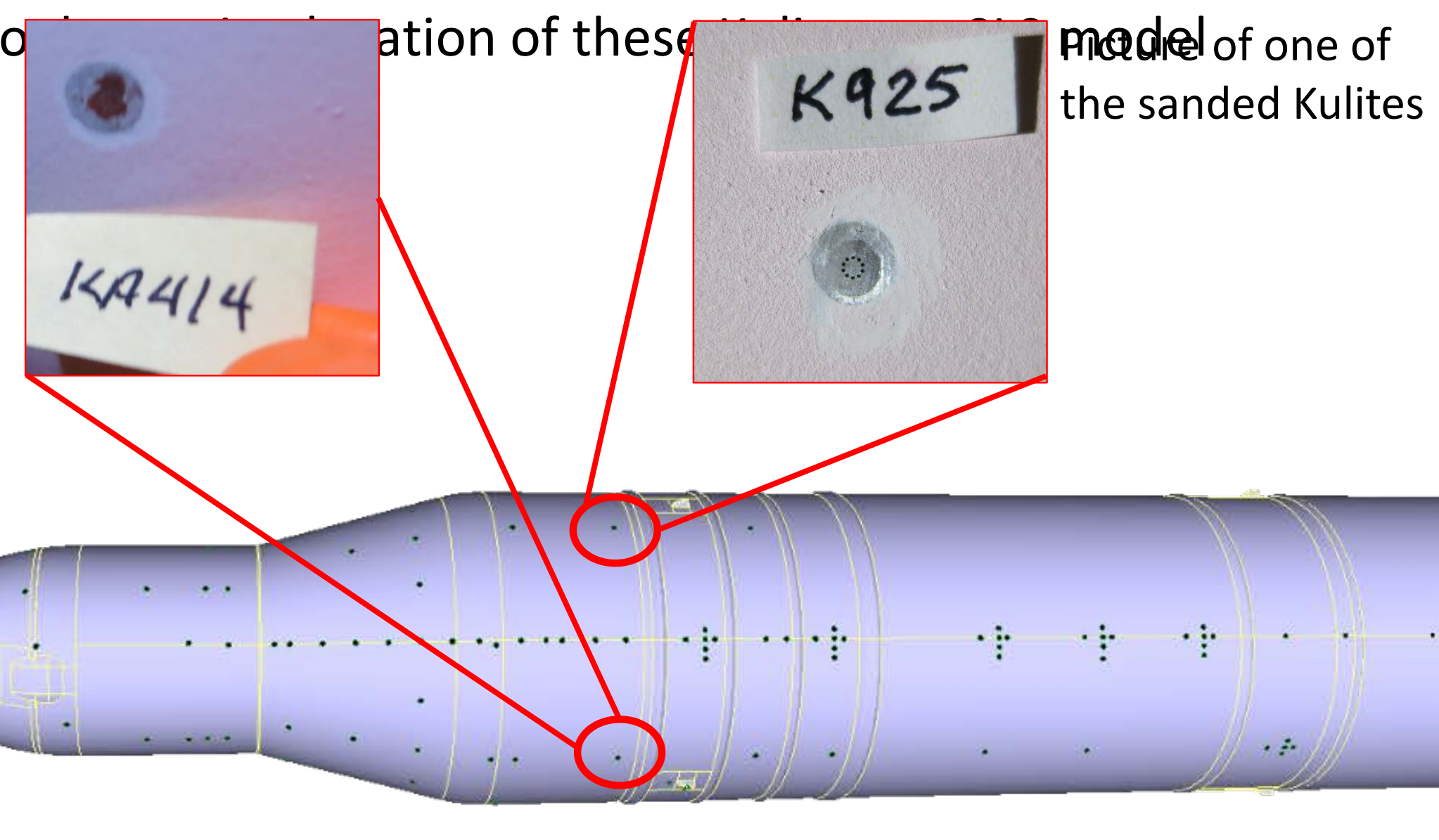




\section{Data Processing Method for Kulites}

- 15 Kulites, 9 Mach Numbers, 4 Days of Testing

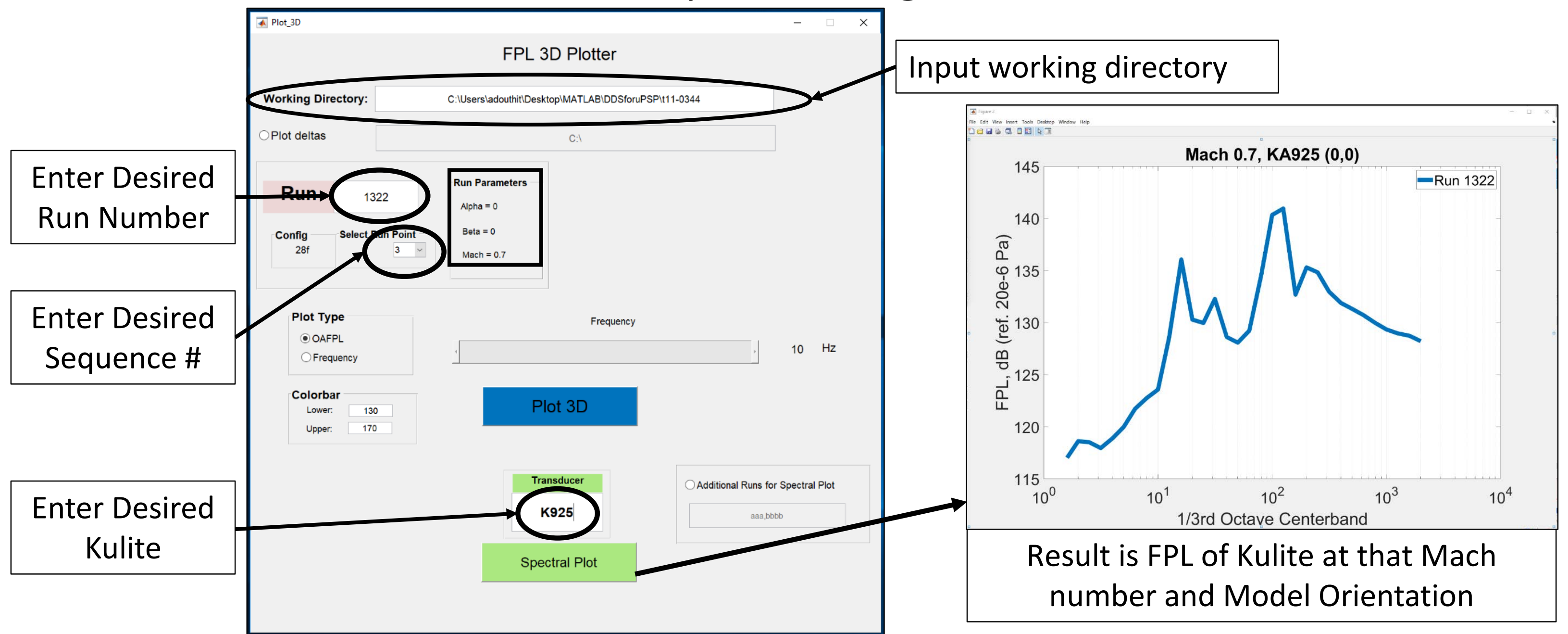




\section{Results of Sanded Kulite Data}


11 DDS Results Along SLS at Mach 0.7, $\alpha=0 \beta=0$ NASA -Day 0

-Day 1

-Day 2

Flow

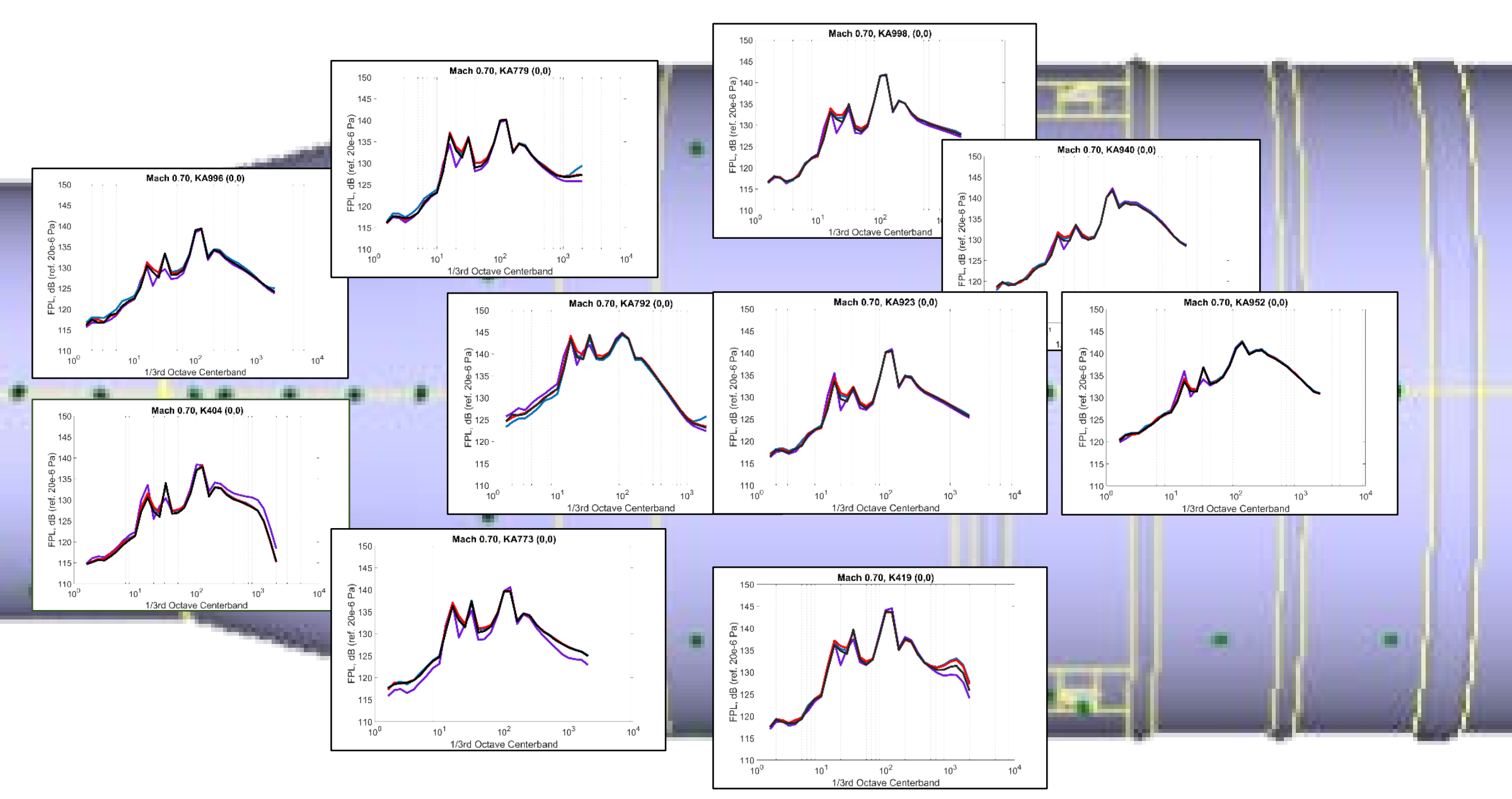


11 DDS Results Along SLS at Mach 0.95, $\alpha=0 \beta=0$ NAsA -Day 0

\section{-Day 1 \\ -Day 2 \\ 一Day 3}

Flow

12 [Dots image courtesy of NASA PSP Team and Thomas Steva of MSFC]

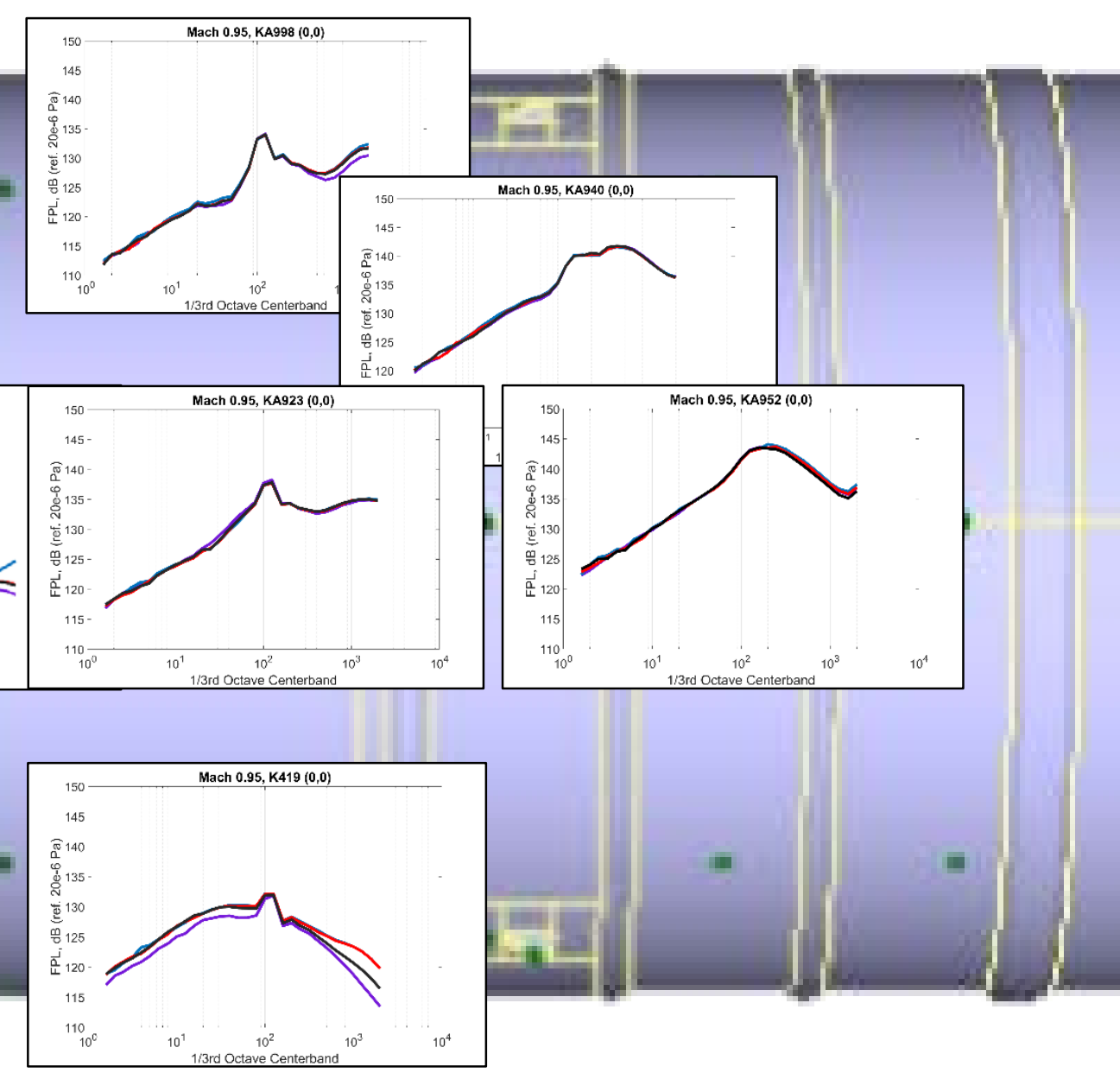

Filut mechamics Lat 


\section{DDS Results Along SLS at Mach 1.4, $\alpha=0 \beta=0$ NASA}

-Day 0

\section{-Day 1 \\ -Day 2 \\ -Day 3}

\section{Flow}




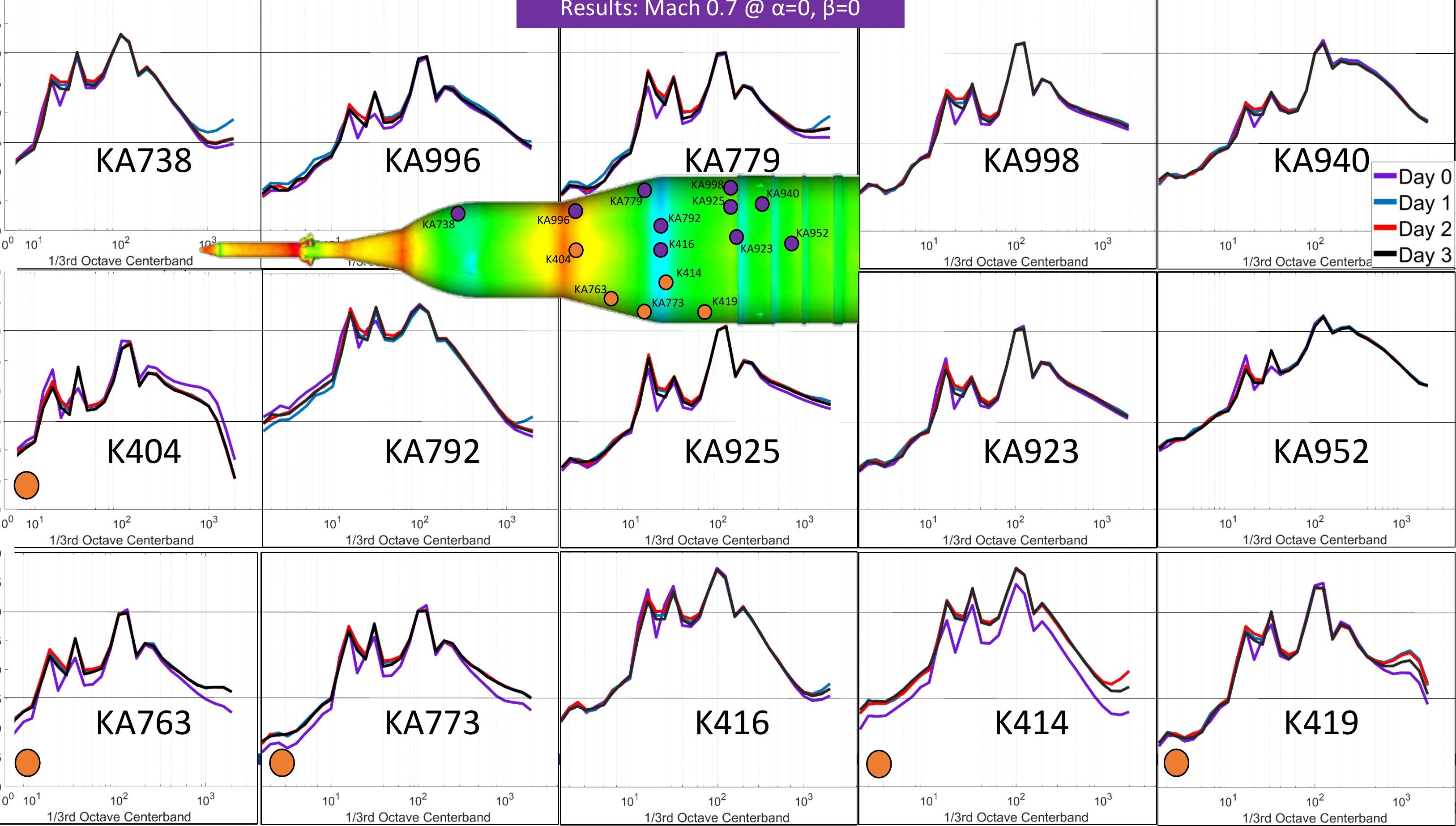


Results with Large Differences in FPL, $\alpha=0 \beta=0$

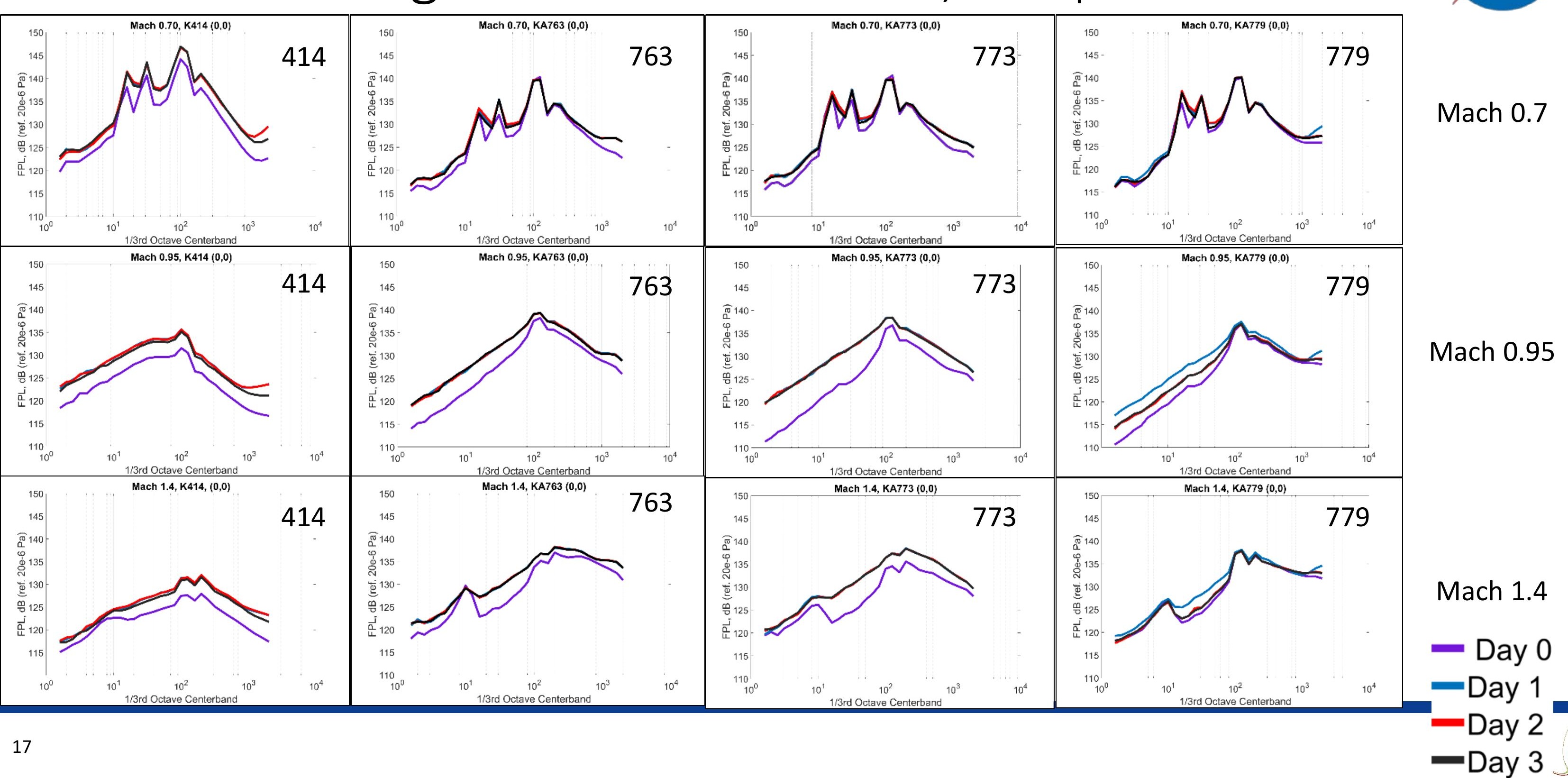




\section{DDS Results Along SLS at Mach 0.7, $\alpha=0 \beta=4$ NasA}

-Day 0

\section{-Day 1 \\ -Day 2 \\ -Day 3}

\section{Flow}

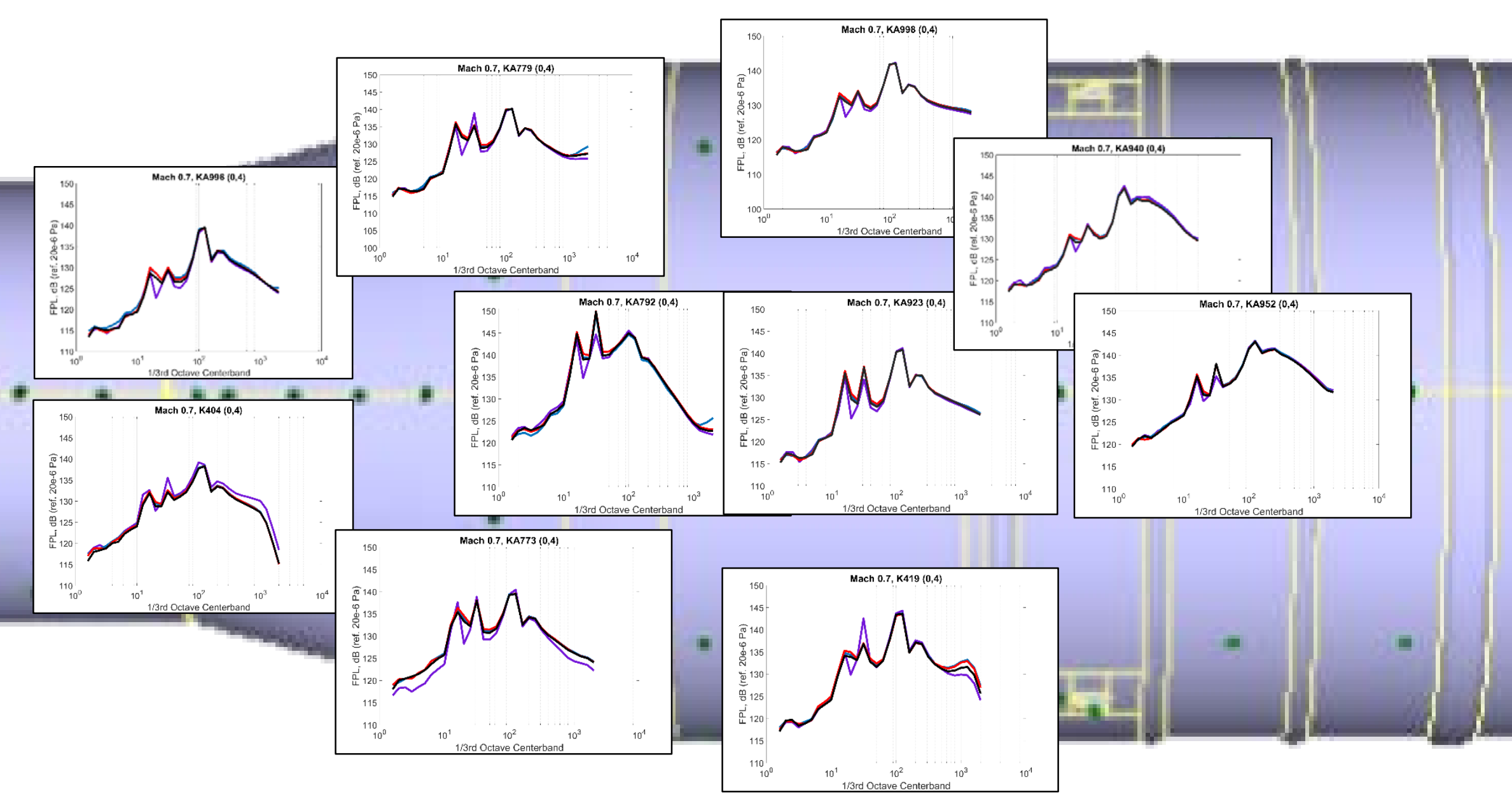




\section{DDS Results Along SLS at Mach 0.95, $\alpha=0 \beta=4$ (NASA}

-Day 0

\section{-Day 1 \\ -Day 2 \\ -Day 3}

\section{Flow}

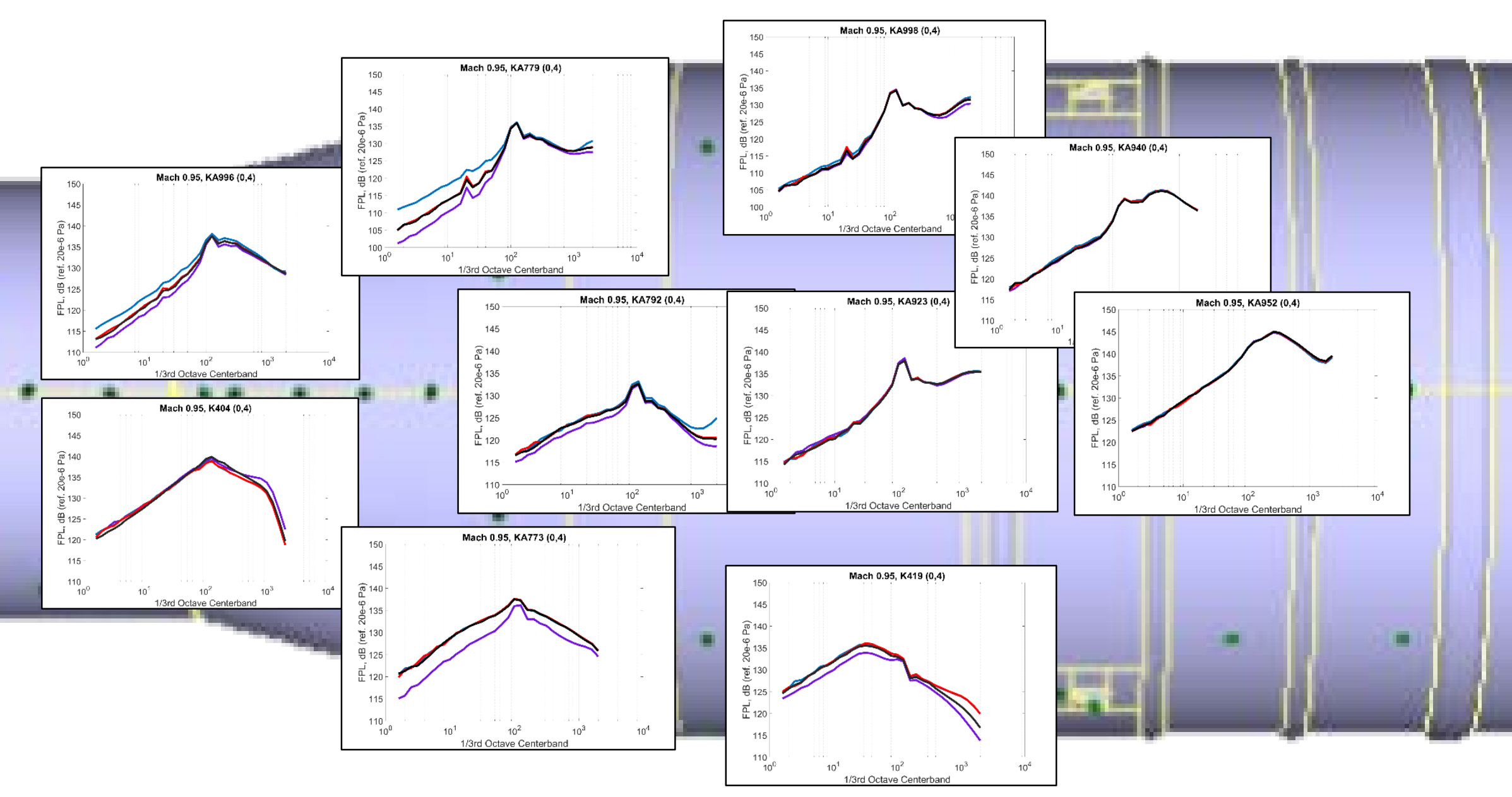




\section{DDS Results Along SLS at Mach 1.4, $\alpha=0 \beta=4$ NasA}

-Day 0

\section{-Day 1 \\ -Day 2 \\ 一Day 3}

\section{Flow}


Results: Mach $0.7 @ \alpha=0, \beta=4$

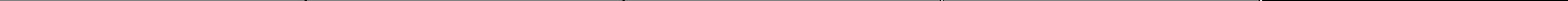




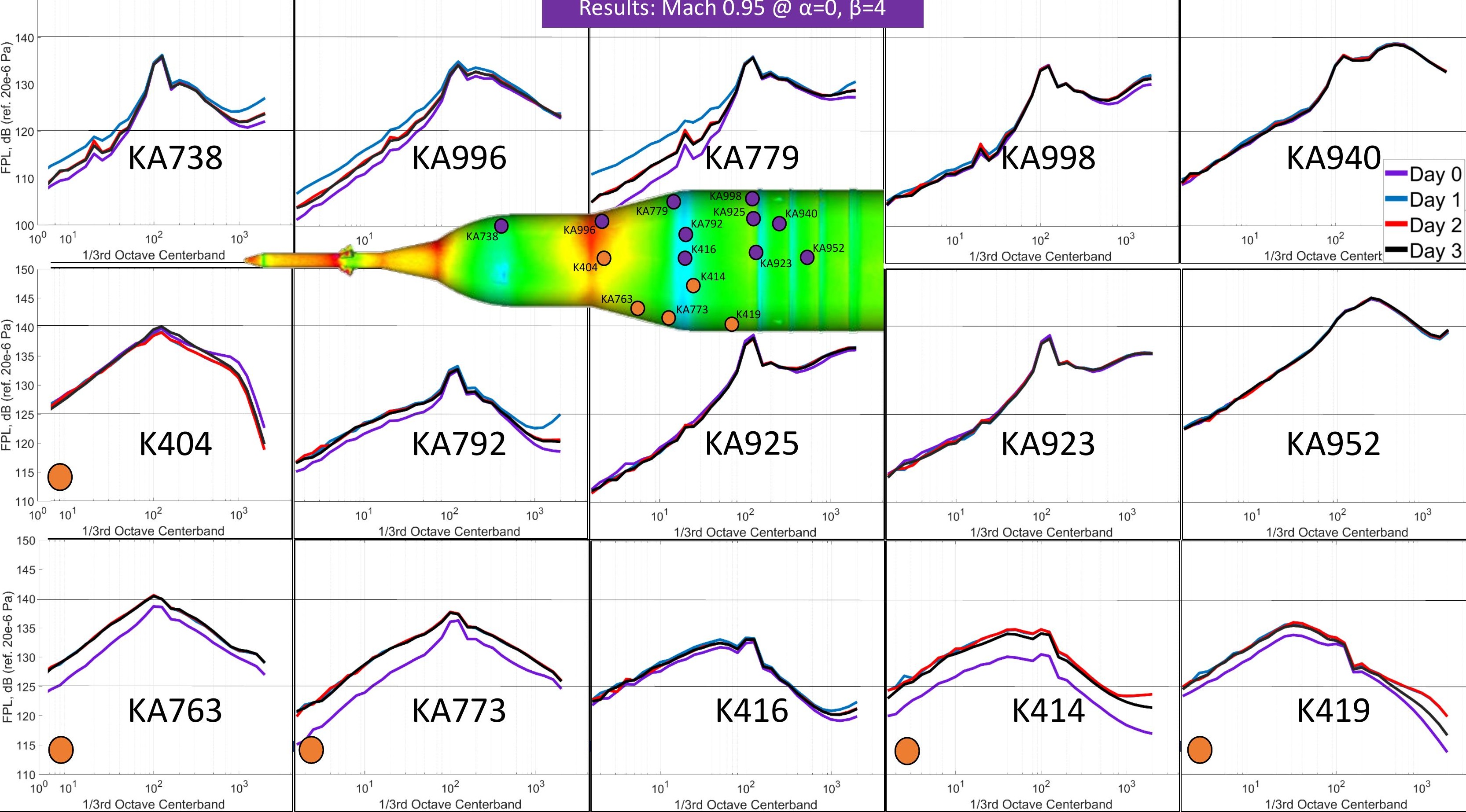




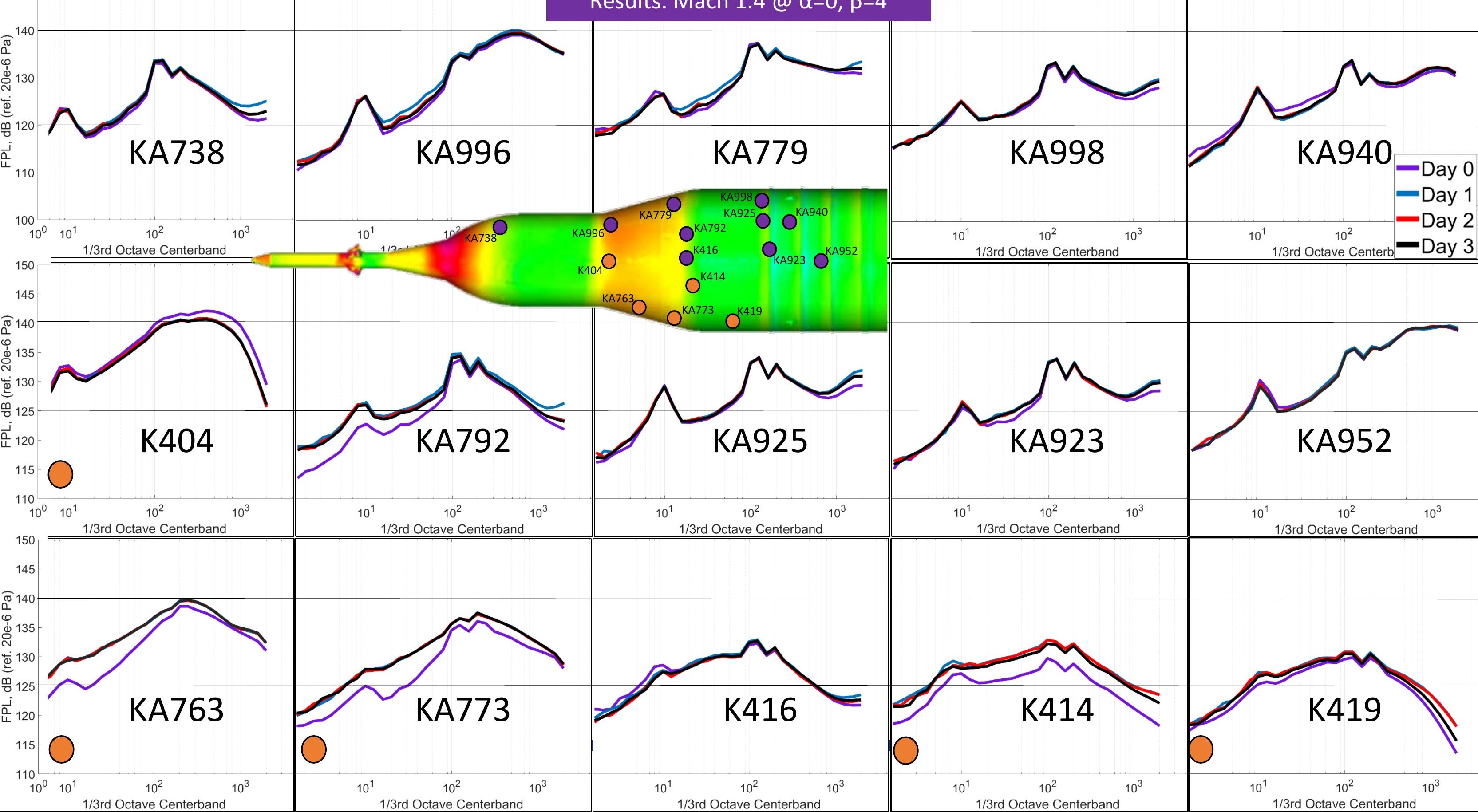




\section{Results with Large Differences in FPL, $\alpha=0 \beta=4$}

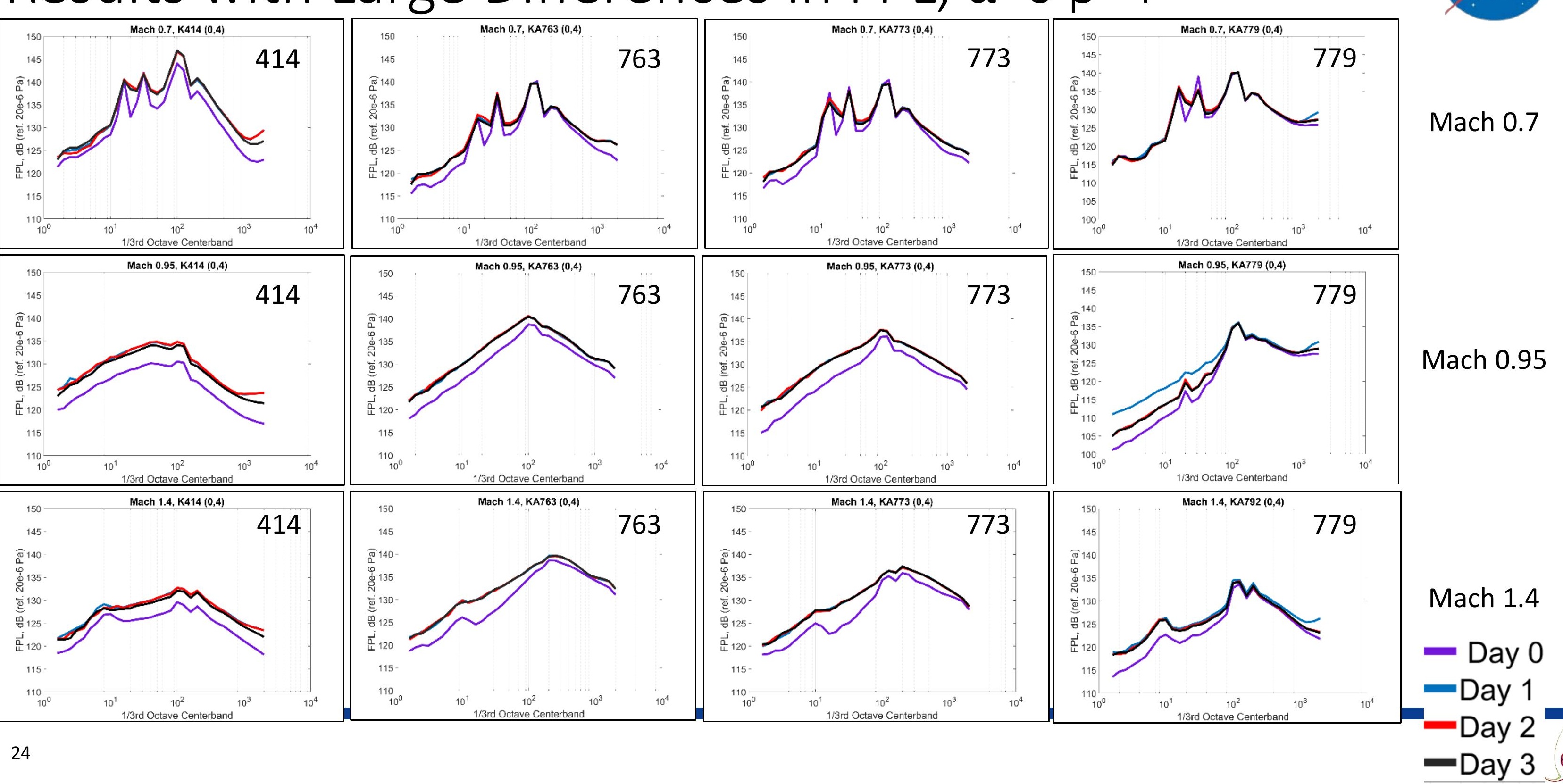




\section{Processing the UPSP Data}




\section{Locating Nodes on SLS using Dots}

- SLS is defined by PSP grid $\rightarrow$ each grid has multiple zones $\rightarrow$ each zone has nodes

- Selected a 3x3 section of nodes near a sanded Kulite using Dots grid

Each node has an $\mathrm{i}$ and $\mathrm{j}$ coordinat

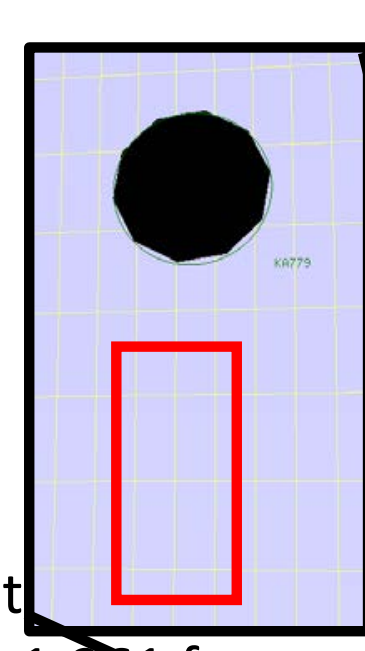

- i coordinate goes around from 1-30x for every line of node in the grids for the largorts of the model

- $\mathrm{J}=1$ at the start of every zone from left toright

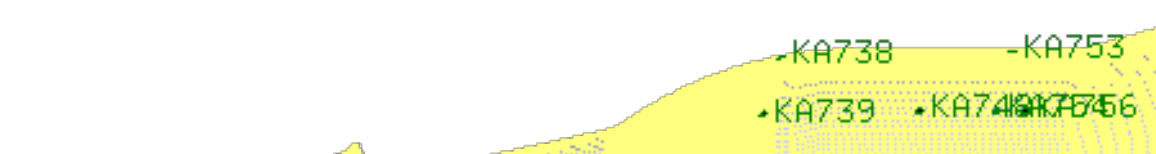

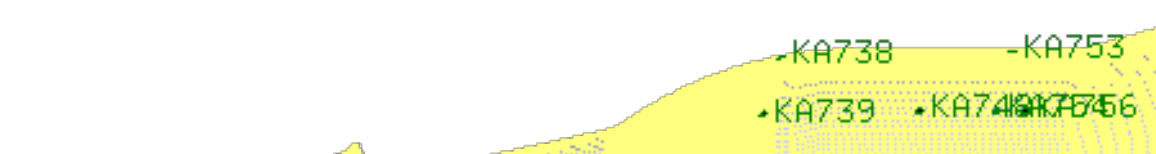
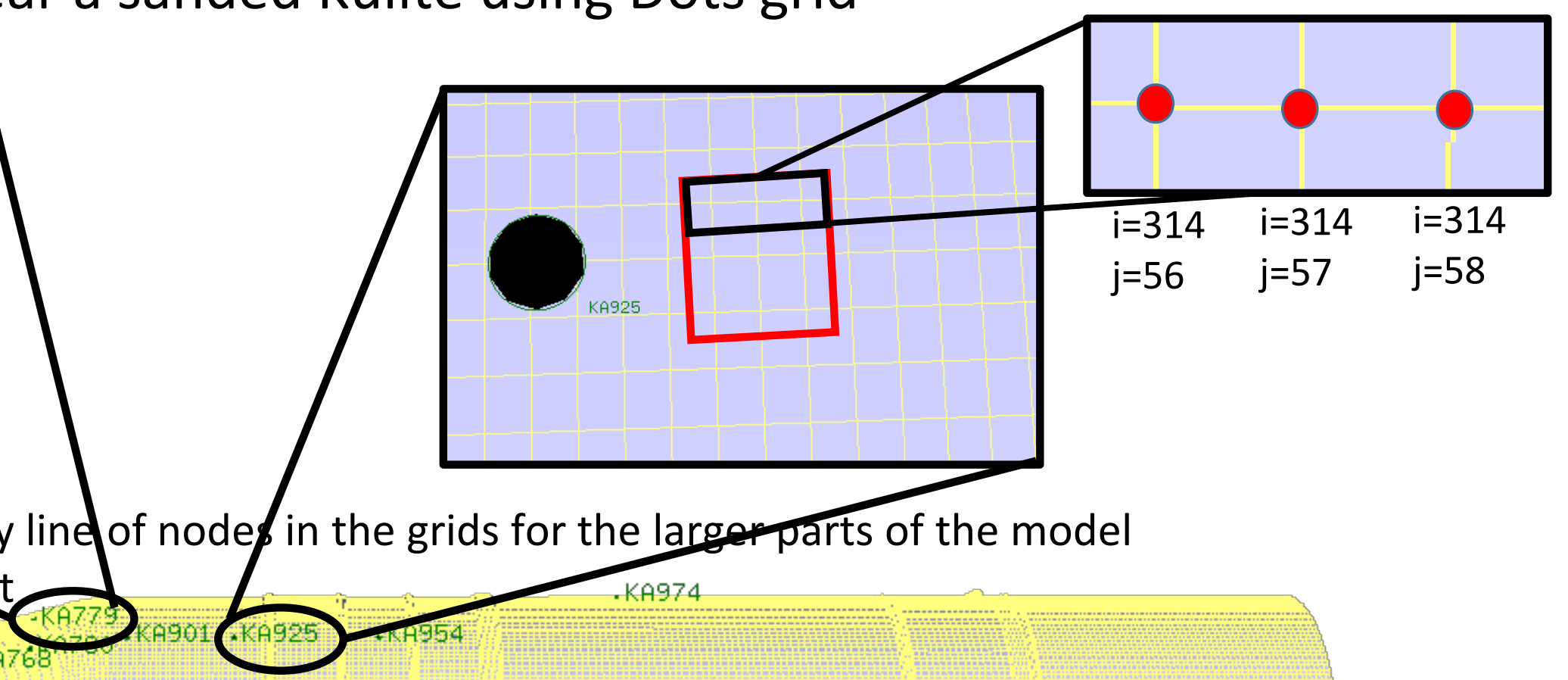

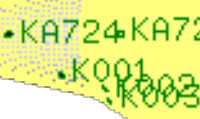

.KA781

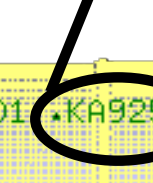

KA974

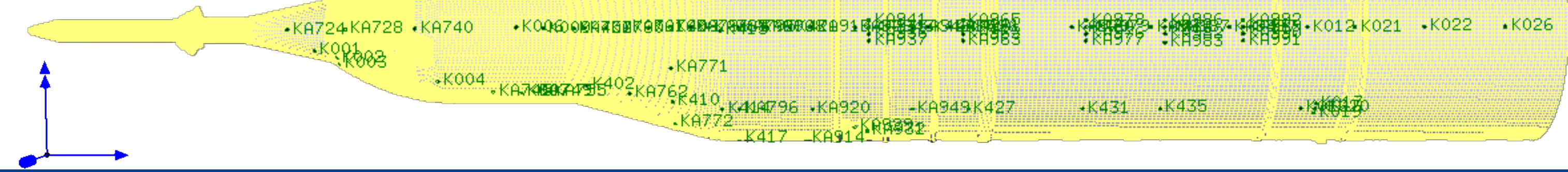

26 [Dots image courtesy of NASA PSP Team and Thomas Steva of MSFC] 


\section{Data Processing Method for UPSP}

- Converted the $3 \times 3$ section of chosen nodes into a virtual Kulite

\&Read HDF 5 file

file $=132506$ trans.h5'

zone $=13$;

obj. $\mathrm{X}=\mathrm{h} 5$ read(file, $\left./ \mathrm{X}^{\prime}\right)$; 8retrieves all $\mathrm{x}$ data for $\mathrm{h} 5 \mathrm{fil}$ bj.Y = h5read(file, '/ $\left./ \mathrm{Y}^{\prime}\right)$; 8 retrieves all $\mathrm{Y}$ data for $\mathrm{h} 5 \mathrm{file}$ obj. $z$ = h5read(file, '/Z'); \&retrieves all z data for h5 file

obj.GridSizes = h5read(file, '/Grid_Sizes');

jmax $=$ obj.Gridsizes $(1$, zone $)$;

kmax $=o b j . G r i d S i z e s(2$, zone $)$

nodes $=0$;

for $i=1:$ zone- 1

nodes $=$ nodes $+($ obj.GridSizes $(1, i)$ * obj.GridSizes $(2, i))$

ode_start $=$ nodes +1

nodes zone $=$ obj.GridSizes (1,zone) ${ }^{*}$ obj.GridSizes $(2$, zone $)$

rode end $=$ node start + nodes zone -1 ;

numofNodes $=$ node_end-node_start +1

clear nodes;

$X=o b j \cdot X$ (node_start:node_end, 1$)$;

$Y=$ obj.Y(node start: node end, 1 )

$z=o b j \cdot z$ (node start:node end, 1 );

$\operatorname{dim} 1=176 ; 8 j$-value or $i$-value in DOTs

$\operatorname{dim} 2=25 ; 8 \mathrm{k}$-value or $\mathrm{j}$-value in DOTS

${ }^{8}$ NZone $=\left[\left(j \max { }^{*} i\right)+\operatorname{dim} 1\right]$

NZone $=[(j \max *(\operatorname{dim} 2-1))+\operatorname{dim} 1]$

KuliteNode $=$ node start + NZone -1

Kulitex $=$ obj.x(KuliteNode $)$

KuliteY $=$ obj.Y(KuliteNode)

Kulitez $=$ obj.z (KuliteNode)
Specified h5 file and zone of nodes

Extracted h5 file information and Grid Sizes;

"jmax" is max of " $i$ " and "kmax" is max of " $j$ " in Dots program for specified zone

Extracting Node Information:

node_start $\rightarrow$ first node in zone in relation to all nodes

nodes_zone $\rightarrow$ number of nodes in specified zone

node_end $\rightarrow$ last node in zone in relation to all nodes

numOfNodes $\rightarrow$ nodes_zone

Specified $(i, j)$ location of node to obtain node number in

specified zone and in relation with all the nodes in Dots program 


\section{Data Processing Method for uPSP Cont.}

\begin{tabular}{|c|c|}
\hline 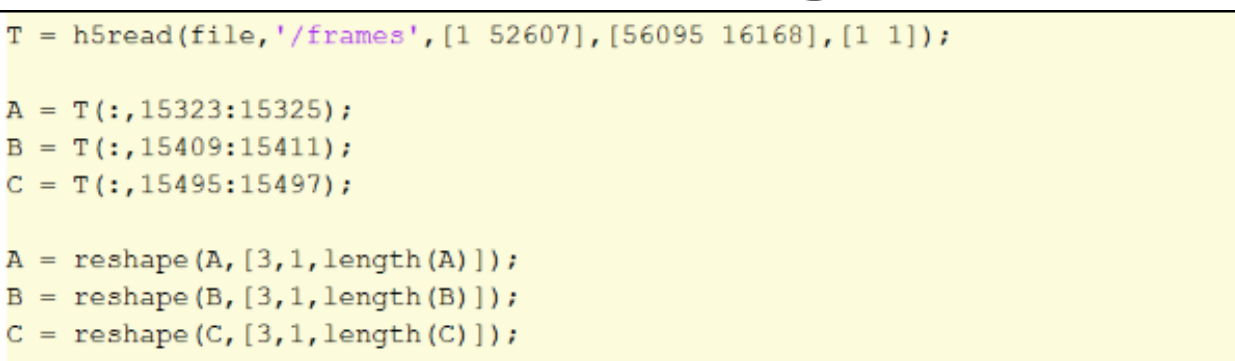 & $\begin{array}{l}\text { Extract the Frame } x \text { Node Data from h5 file } \\
\text { Isolate chosen nodes in columns perpendicular to flow for } 3 \\
\text { vectors } \\
\text { Reshape these into } 3 \times 1 \text { xtime matrices }\end{array}$ \\
\hline $\begin{array}{l}\text { SCombine the matrixes above into a } 3 \times 3 \times \text { time matrix } \\
\mathrm{D}=\text { cat }(2, \mathrm{~A}, \mathrm{~B}, \mathrm{C}) \text {; } \\
\text { Saverage these to create a virtual Kulite } \\
\mathrm{K}=\text { mean }(\text { mean }(\mathrm{D}), 2) \text {; } \\
\text { 8to reshape into a } 2 \mathrm{Datrix} \ldots \\
\mathrm{K}=\text { reshape }(\mathrm{K},[1, \text { length }(\mathrm{K})]) ;\end{array}$ & $\begin{array}{l}\text { Combine the matrices into one } 3 \times 3 x \text { time matrix } \\
\text { Average matrix to create virtual Kulite, now a } 1 \times 1 x \text { time matrix } \\
\text { Reshape into } 2 \mathrm{D} \text { matrix (1xtime) }\end{array}$ \\
\hline 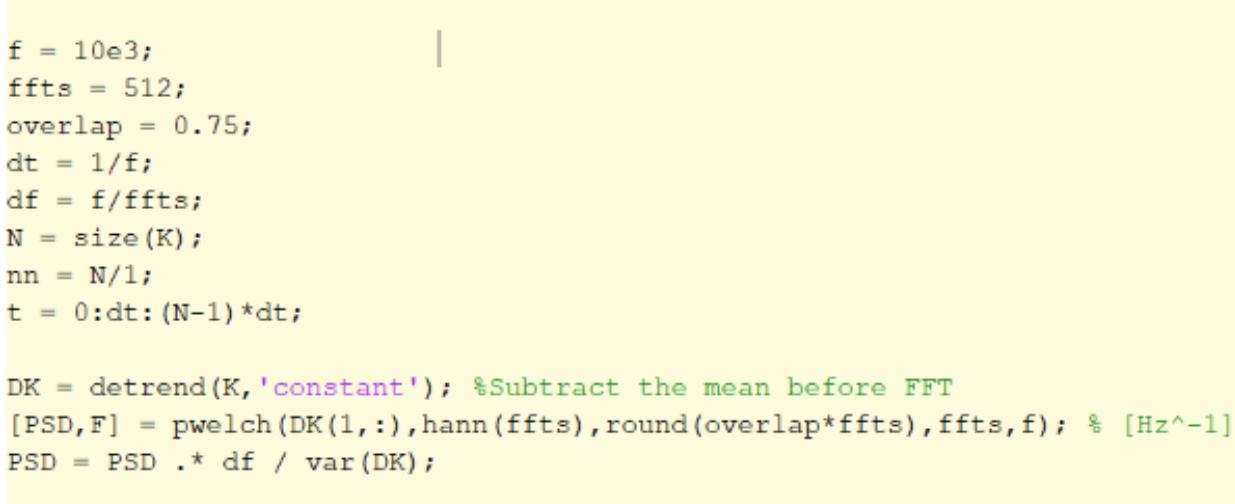 & $\begin{array}{l}\text { Processed uPSP data to obtain Power Spectral Density plot } \\
\text { Sampling Rate } \rightarrow 10 \mathrm{kHz} \\
\text { FFT size } \rightarrow 512 \\
\text { Overlap } \rightarrow 0.75 \\
\text { Detrended virtual Kulite (although not needed) } \\
\text { Normalized by variance of detrended data }\end{array}$ \\
\hline 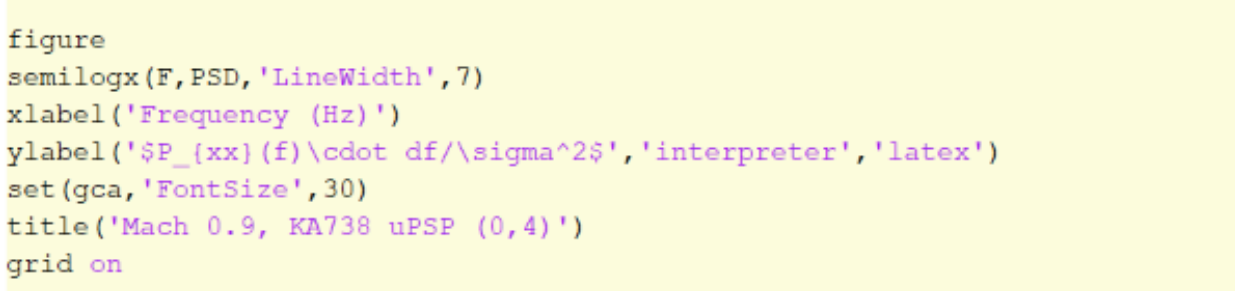 & Plotting PSD in semilog fashion \\
\hline
\end{tabular}




\section{Conclusions Gathered to Help Complete the Mission}

- No right or wrong answer

- Changing the roughness of a model will affect the flow

- Positive Note: UPSP not creating tones $\rightarrow$ not translating to design change

- UPSP surface roughness does affect flow, magnified at areas of high fluctuating pressures (do see offset but consistent across days)

Future Work Towards Mission Accomplishment

- Process UPSP data for same runs

- Prepare for September uPSP demonstration

- Only sanding in areas of high fluctuation

- Painting over Kulites $\rightarrow$ does uPSP damage the Kulite? 


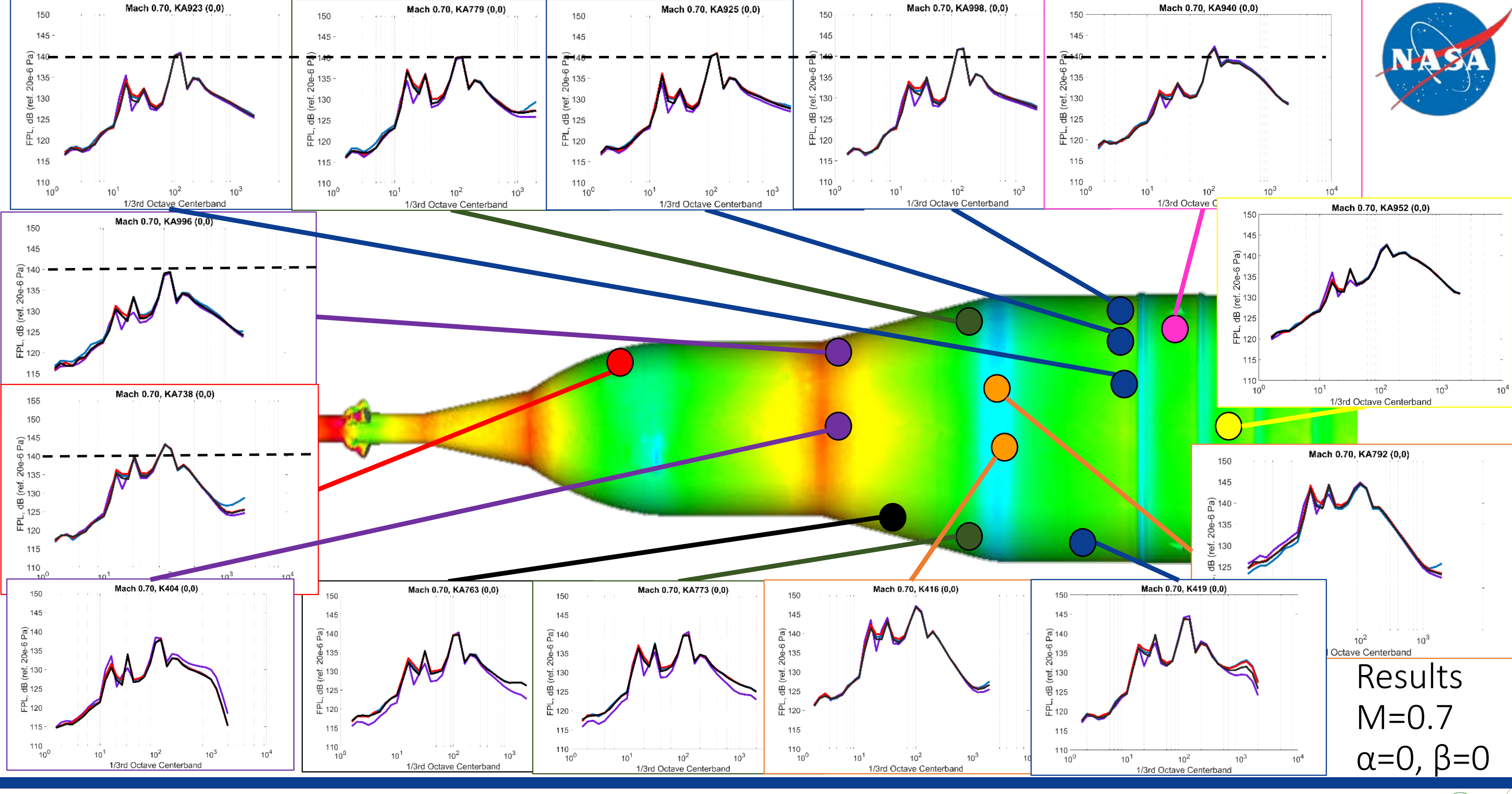


Results $140 \mathrm{~dB}$

$M=0.7$
$\alpha=0, \beta=0$

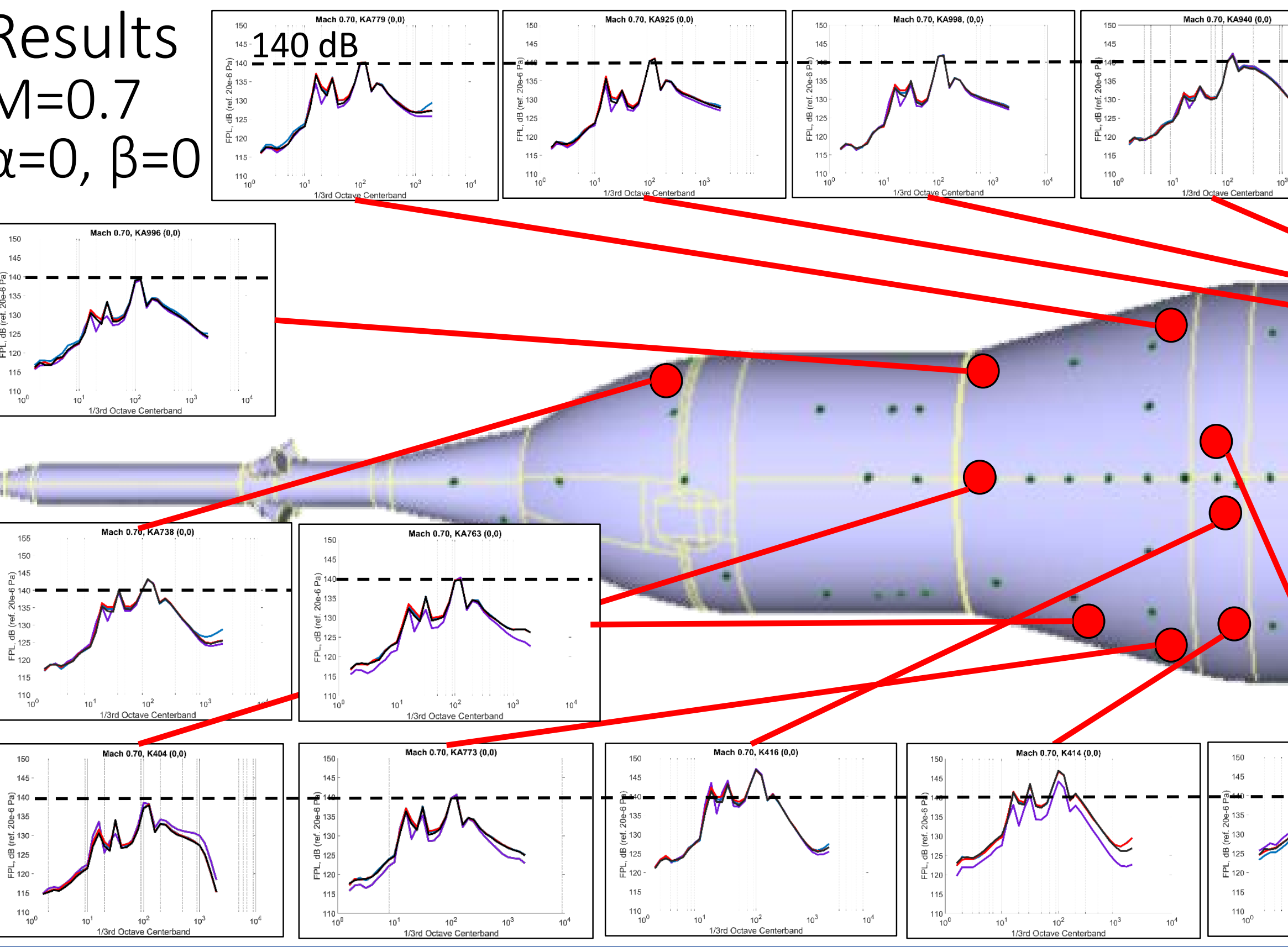

Mach 0.70, KA998, (0,0)

33 [Dots image courtesy of NASA PSP Team and Thomas Steva of MSFC] 
Results
$M=0.95$
$\alpha=0, \beta=0$
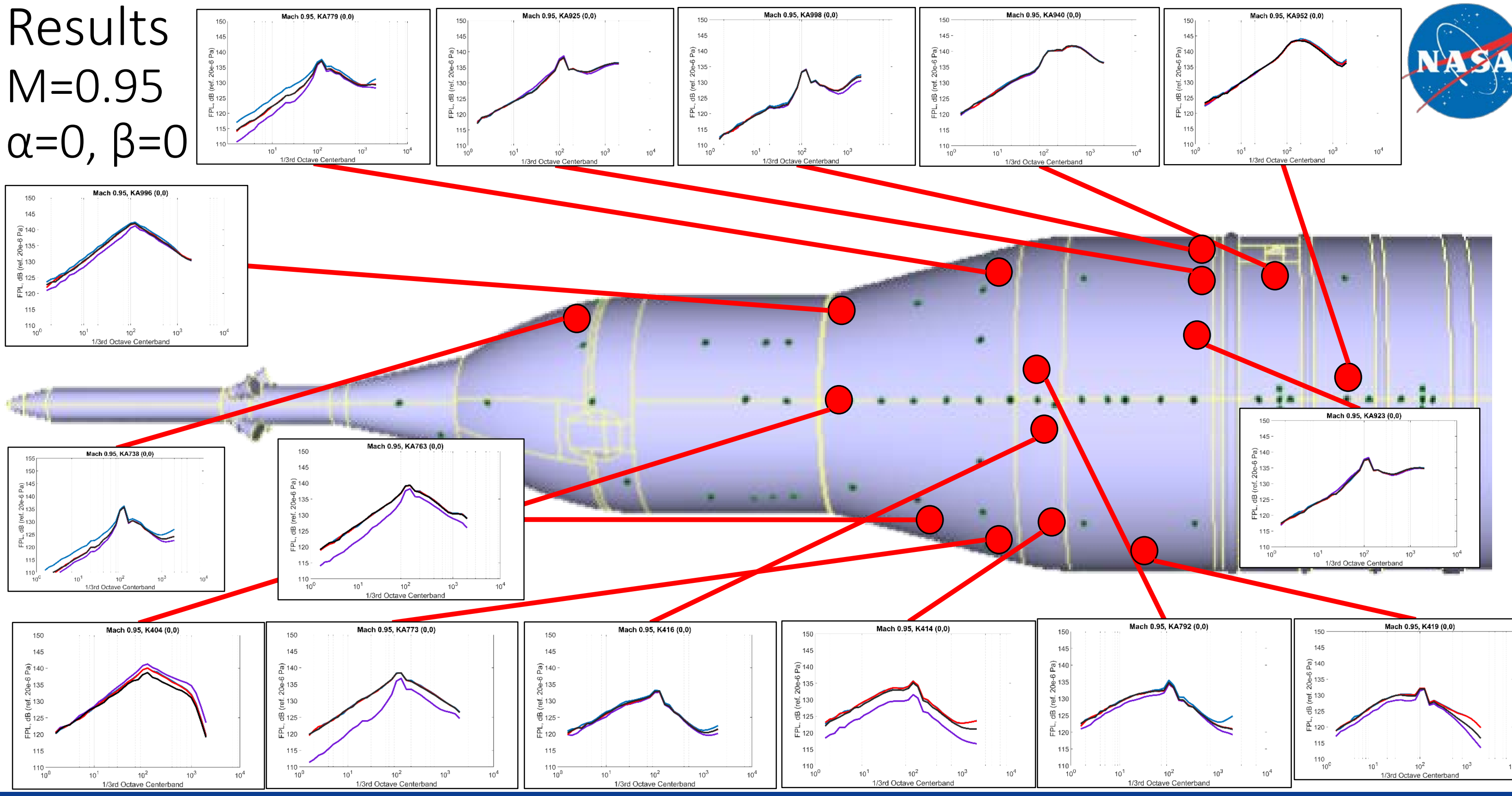
Results

$M=0.7$

$\alpha=0, \beta=4$
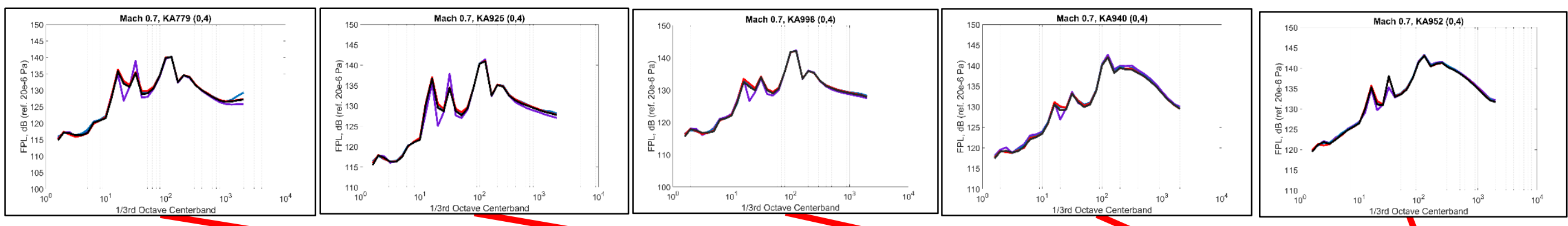

NASA

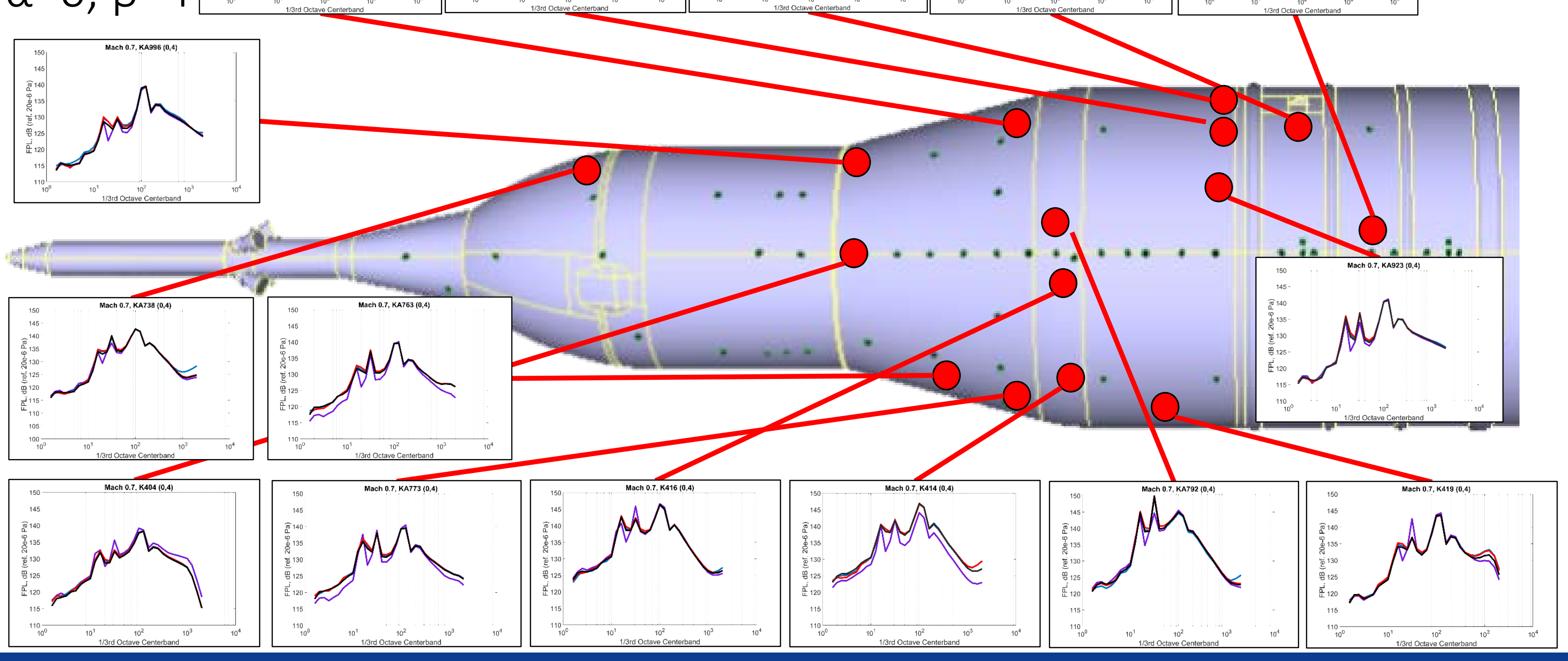

36 [Dots image courtesy of NASA PSP Team and Thomas Steva of MSFC] Auld mechanus lat 
